\title{
Argus II retinal prosthesis implantation with scleral flap and autogenous temporalis fascia as alternative patch graft material: a 4-year follow-up
}

This article was published in the following Dove Press journal:

Clinical Ophthalmology

18 August 2016

Number of times this article has been viewed

\author{
Alexandre Matet ${ }^{1,2}$ \\ Nawel Amar ${ }^{1,2}$ \\ Saddek Mohand-Said ${ }^{1-4}$ \\ José-Alain Sahel ${ }^{1-7}$ \\ Pierre-Olivier Barale ${ }^{1,2}$ \\ 'INSERM and DHOS, CHNO des \\ Quinze-Vingts, ${ }^{2}$ Sorbonne Universités, \\ UPMC Univ Paris 6, Institut de la \\ Vision, ${ }^{3}$ INSERM, ${ }^{4} \mathrm{CNRS}$, Paris, \\ France; ${ }^{5}$ nstitute of Ophthalmology, \\ University College London, London, \\ UK; ${ }^{6}$ Fondation Ophtalmologique \\ Adolphe de Rothschild, ${ }^{7}$ Académie \\ des Sciences, Institut de France, \\ Paris, France
}

Introduction: The Argus II retinal prosthesis is composed of an epiretinal electrode array positioned over the macula and connected to an extrascleral electronics case via a silicone cable, running through a sclerotomy. During implantation, the manufacturer recommends to cover the sclerotomy site with a patch of processed human pericardium to prevent postoperative hypotony and conjunctival erosion by the underlying electronics case. Due to biomedical regulations prohibiting the use of this material in France, we developed an alternative technique combining a scleral flap protecting the sclerotomy and an autogenous graft of superior temporalis fascia overlying the electronics case.

Methods: The purpose of this study is to describe the 4-year outcomes of this modified procedure in three subjects who underwent Argus II Retinal Prosthesis System implantation. Clinical data consisting of intraocular pressure measurements and tolerance in terms of conjunctival erosion or inflammation were retrospectively assessed over a 4-year postoperative follow-up.

Results: None of the three patients implanted with the modified technique developed ocular hypotony over 4 years. A normal, transient conjunctival inflammation occurred during the first postoperative month but conjunctival erosion was not observed in any of the three patients over 4 years. Four years after implantation, the autogenous temporalis fascia graft remained well tolerated and the retinal prosthesis was functional in all three patients.

Conclusion: The combination of an autograft of superficial temporalis fascia and a scleral flap efficiently prevented leakage through the sclerotomy site, ocular hypotony, and conjunctival erosion by the extrascleral electronics case. This modified technique is suitable for the implantation of existing and forthcoming retinal prostheses. Superficial temporalis fascia may also be used as alternative to commercial tectonic tissues for scleral wound repair in clinical settings where they are not available.

Keywords: visual prosthesis, retinitis pigmentosa, surgical procedure, conjunctiva, intraocular pressure

\section{Introduction}

The Argus II Retinal Prosthesis System (Second Sight Medical Products Inc., Sylmar, CA, USA) has received marketing authorizations by the US Food and Drug Administration and the European regulatory authorities. In several countries, including Germany, the Netherlands, UK, Spain, Italy, France, Switzerland, Saudi Arabia, the US, and Canada, patients presenting end-stage retinitis pigmentosa but maintaining a functional inner retinal circuitry are potential candidates for implantation. ${ }^{1}$ A 30-participant prospective study ${ }^{2,3}$ and additional investigations demonstrated visual and behavioral improvement in a majority of implanted subjects after visual rehabilitation. ${ }^{4-8}$ The retinal prosthesis consists of an electrode array placed on the
Correspondence: Pierre-Olivier Barale $\mathrm{CHNO}$ des Quinze-Vingts, 28 rue de Charenton, F-75012 Paris, France

Tel +33 | 4002 I4 04

Fax +33 I 4002 I4 45

Email pobarale@wanadoo.fr 
macular area, connected via a silicone cable across the sclera to an extraocular electronics case. According to recommendations for the standard implantation procedure, the surgeon must perform a $5 \mathrm{~mm}$ direct pars plana sclerotomy, across which will run the cable connecting the macular electrode array to the extraocular electronics case, and finally to cover efficiently both sclerotomy site and electronics case with a biocompatible patch material to seal the wound and prevent conjunctival erosion by the extraocular case. ${ }^{9}$ The manufacturer recommends as patch graft material the use of processed human pericardium. However, in several countries including France, processed pericardium is not commercially available due to biomedical regulations prohibiting its use, which prompted us to adapt the implantation procedure. We present an alternative surgical technique for retinal prosthesis implantation that overcomes these legal restrictions on processed human cadaveric pericardium by using an autograft of superficial temporalis fascia.

\section{Methods}

\section{Adapted surgical technique}

The modified procedure incorporated two main changes. First, instead of a direct sclerotomy, a $5 \mathrm{~mm}$ wide scleral flap was performed in order to protect the sclerotomy site. Second, instead of processed human cadaveric pericardium, or polytetrafluoroethylene, an alternative patch graft material initially recommended by the tissue bank at our institution, the sclerotomy site was covered by an autogenous graft of temporalis fascia (Figure 1), sampled from the patient's temporal scalp at the beginning of the implantation procedure. Table 1 lists the recommended and adapted surgical steps. Briefly, under general anesthesia, a $3 \mathrm{~cm}$ cutaneous and subcutaneous incision was performed in the right
A

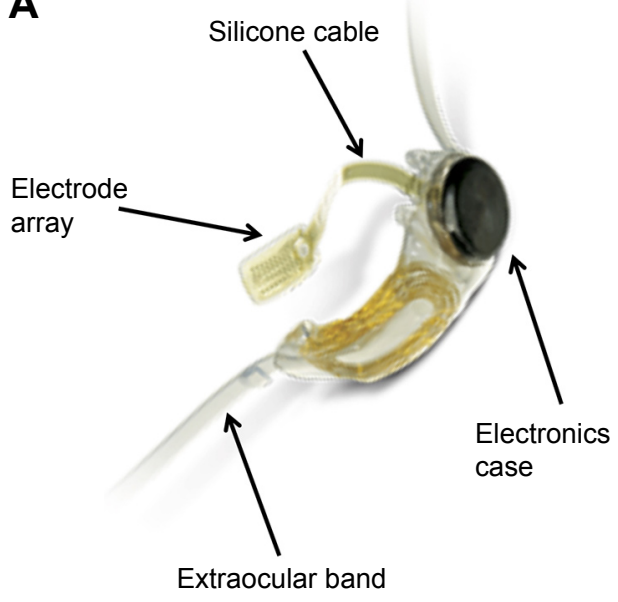

B

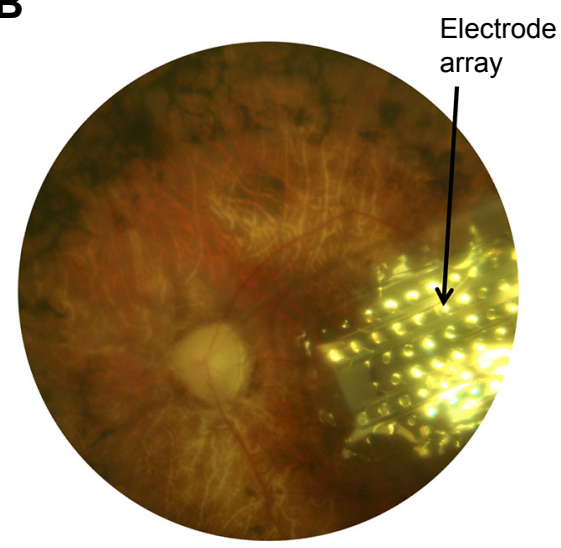

C

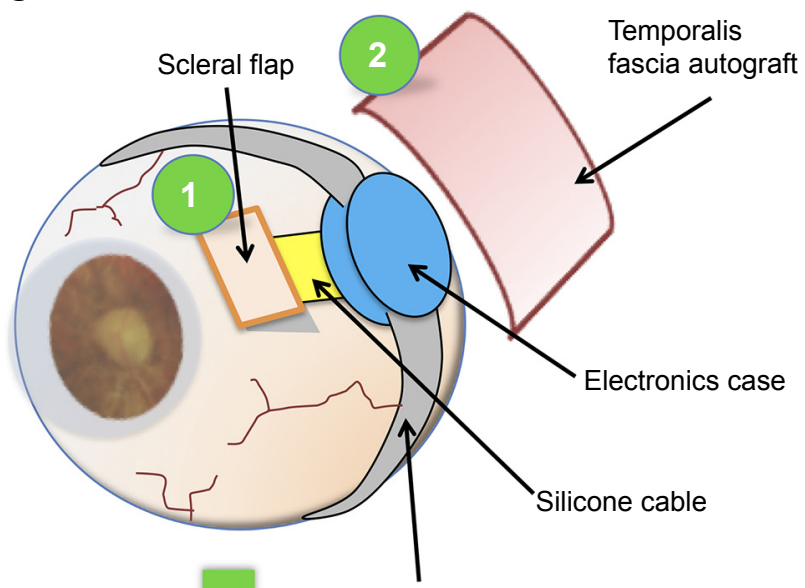

Extraocular band

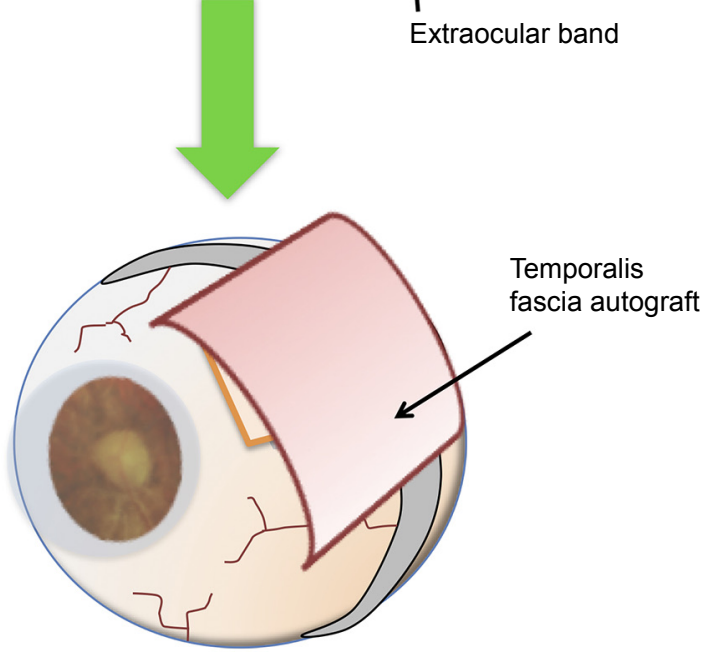

Figure I (A) Structure of the Argus II Retinal Prosthesis System showing the electrode array, its silicone cable connected to the extraocular electronics case, and the band used for extrascleral fixation. (B) Fundus photograph showing the position of the electrode array over the macula in a patient with retinitis pigmentosa. (C) Schematic adapted technique for retinal prosthesis implantation with a scleral flap at the sclerotomy site (I) and an autograft of superior temporalis fascia (2). Before closure of Tenon's capsule and conjunctiva, the temporalis fascia covers both the scleral flap and the extraocular electronics case.

Note: (A) Copyright (C). Reproduced from Second Sight Medical Products, Inc. System Overview [webpage on the Internet]. Sylmar, CA: Second Sight Medical Products, Inc.; 2016. Available from: http://www.secondsight.com/system-overview-en.html. Accessed August 2, 2016. ${ }^{32}$ Argus II Retinal Prosthesis System (Second Sight Medical Products, Inc., Sylmar, CA, USA). 
Table I Manufacturer's protocol and adapted steps for Argus II retinal prosthesis implantation

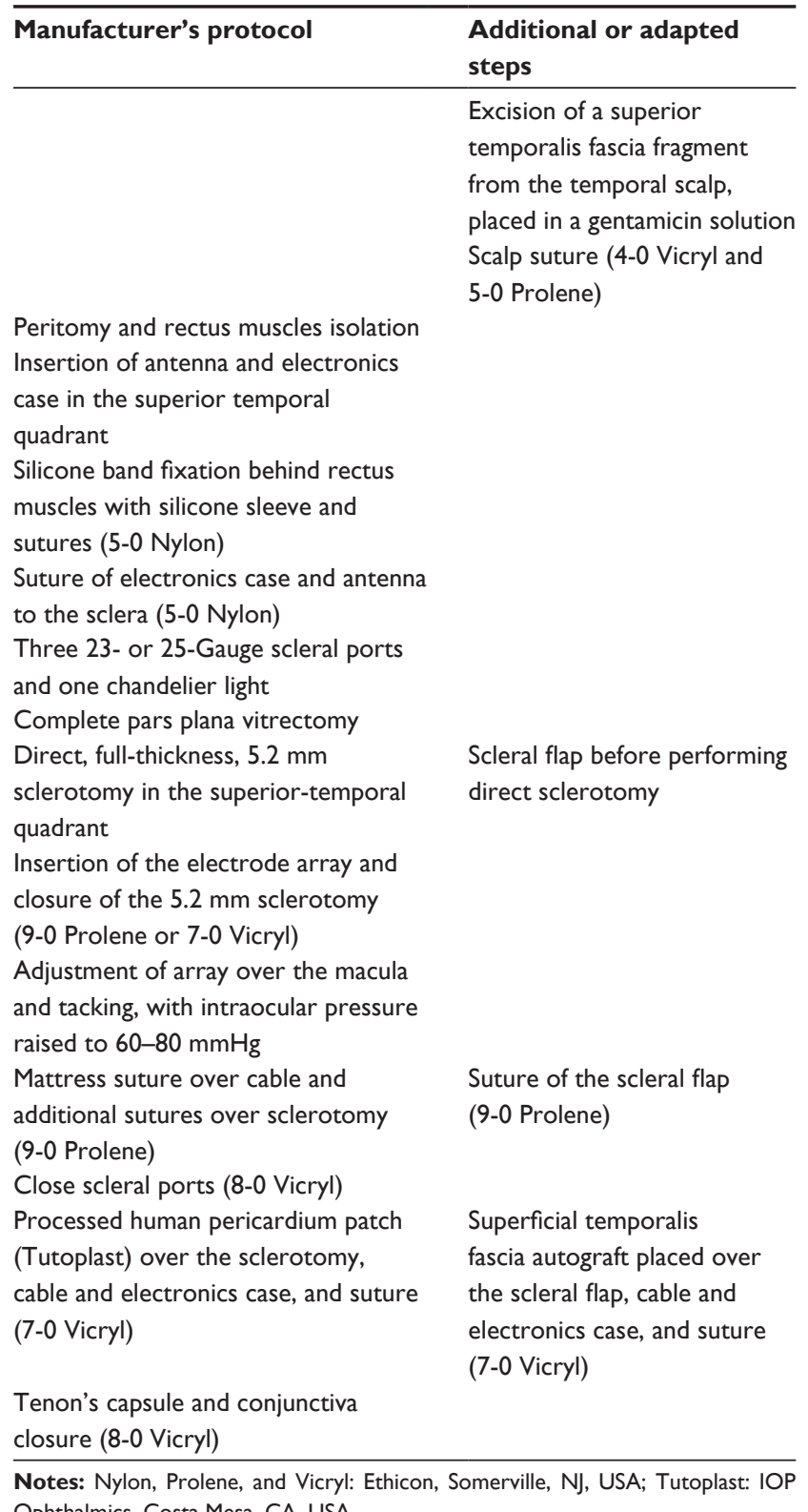

Ophthalmics, Costa Mesa, CA, USA.

temporal scalp, posterior and superior to the ear, after local hair shaving. A $3 \times 1 \mathrm{~cm}$ fragment of superficial temporalis fascia was excised (Figures 2 and 3), corresponding to the first musculotendinous structure accessed below the subcutaneous adipose tissue. After achieving careful hemostasis, the temporal wound was then sutured using a 4-0 polyglactin 910 absorbable suture (Vicryl; Ethicon, Somerville, NJ, USA) for the subcutaneous tissues and a 5-0 polypropylene intradermic suture for the skin (Prolene; Ethicon). A $5 \times 7 \mathrm{~mm}$ fragment of temporalis fascia was prepared and preserved in a gentamicin antibiotics solution (Gentamicin, $20 \mathrm{mg} / \mathrm{mL}$; Panpharma, Fougères, France). After intraocular implantation of the retinal prosthesis and positioning of the extraocular electronics case fixed onto the sclera by its silicone band, according to the manufacturer's instructions, ${ }^{9}$ the temporalis fascia autograft was positioned onto the sclera in order to cover both the sclerotomy site and the extraocular case. It was sutured using a 6-0 absorbable suture (Vicryl; Ethicon), before closure of the overlying Tenon's capsule, and finally the conjunctiva were closed above the fascia autograft using a 8-0 absorbable suture (Vicryl; Ethicon). As recommended by the manufacturer, the patients received daily oral levofloxacine (500 mg; Biogaran, Colombes, France) from 48 hours before, until 7 days after the procedure, and a single dose of intravenous cephazolin (1 g; Mylan, Saint Priest, France) at the start of the procedure.

\section{Subjects}

Three patients who underwent Argus II retinal prosthesis implantation between January and May 2009 at our institution during an international clinical trial ${ }^{2,3}$ and who benefited from this modified surgical technique were retrospectively included. This study describing surgical procedures and outcomes in human participants was designed in accordance with the Tenets of the 1964 Declaration of Helsinki and its later amendments. The study followed the ethical standards from the local ethics committee (CPP Ile-de-France 5, SaintAntoine Hospital, Paris) and the need of formal informed consent was waived by the Quinze-Vingts Hospital internal review board due to the retrospective nature of the study.

Intraocular pressure (IOP) measurements were performed by noncontact tonometer (Tonoref II; Nidek, Gamagori, Japan). Three measures were performed by the device and the mean IOP was recorded. IOP values below 10 or above $20 \mathrm{mmHg}$ were verified using Goldman aplanation tonometry. Conjunctival inflammation was assessed qualitatively by estimating the degree of conjunctival hyperemia and swelling. Conjunctival integrity was evaluated by fluorescein staining, and erosion was diagnosed when loss of conjunctival tissue was observed above subconjunctival material (electronics case, fascia temporalis, sutures).

To evaluate, in patients receiving the Argus II retinal prosthesis, the efficacy and tolerability of autogenous temporalis fascia as alternative patch graft material, IOP, signs of conjunctival inflammation, and conjunctival integrity were retrospectively assessed at regular interval during a 4-year follow-up.

\section{Results}

The modified procedure was performed in three patients (patients 1-3). No patient developed hypotony, neither during the immediate postoperative period nor during the 


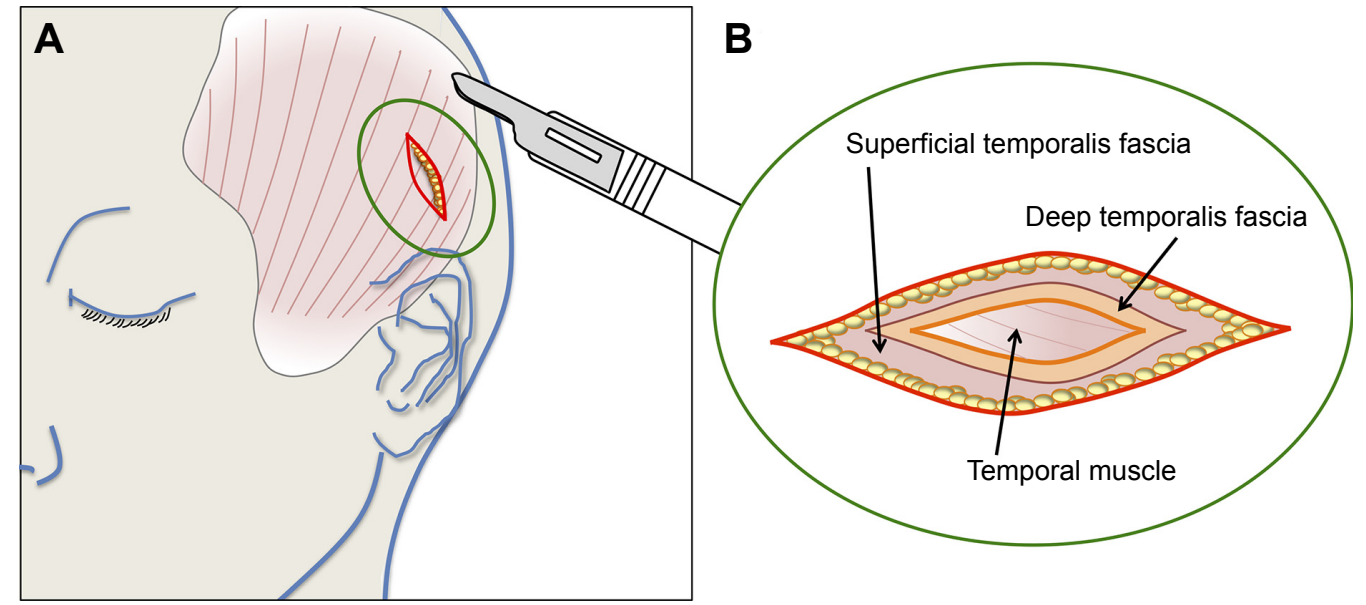

Figure 2 Schematic drawing of the surgical anatomy of the temporal scalp region.

Notes: (A) Anatomical drawing of the temporal muscle and the recommended localization for the incision site. (B) Surgical anatomy of the superficial and deep temporalis fascia layers overlying the temporal muscle. In the adapted retinal prosthesis implantation procedure, the superficial temporalis fascia, localized immediately beneath the subcutaneous adipose tissue, was excised.

4-year follow-up. In patients 1 and 2, IOP measurements were between 14 and $22 \mathrm{mmHg}$ during the first postoperative month. Patient 3 developed a mild postoperative IOP elevation 1 week after surgery $(25 \mathrm{mmHg})$ that responded to topical beta-blocker therapy (timolol 1\%, twice daily; Sandoz, Holzkirchen, Germany), and all ulterior IOP measurements were within the normal range. Over the next 4 years, all IOP values were measured between 10 and $19 \mathrm{mmHg}$ in the three patients, with mean IOP values of $16.0 \mathrm{mmHg}$ (range, 14-18 mmHg) at 1 month, $17.3 \mathrm{mmHg}(16-19 \mathrm{mmHg})$ at 3 months, $17.0 \mathrm{mmHg}(16-18 \mathrm{mmHg})$ at 1 year, and 17.0 $\mathrm{mmHg}(15-19 \mathrm{mmHg})$ at 4 years (Figure 4).

All three patients presented transient postoperative conjunctival inflammation related to the surgical de- and re-insertion of the conjunctiva, which resolved over 1 month under topical dexamethasone/trobramycin drops (four times daily; Alcon, Rueil-Malmaison, France). Over the 4-year follow-up period, neither conjunctival erosion nor abnormal conjunctival inflammation was observed in any of the three patients. Photographs showing the temporal conjunctiva of patients 1-3 at the 4-year follow-up visit, corresponding to the site of the implanted electronics case covered by temporalis fascia, are provided in Figure 5.

At the excision site on the temporal scalp, the scar was no longer visible after a normal healing process of a few months, in all three cases (Figure 3).

No adverse events were observed after implantation of the retinal prosthesis with this alternative technique. In particular, there was no donor-site morbidity, no functional or esthetic complications in the temporal area, and the Argus II system was functional and well tolerated 4 years after implantation.
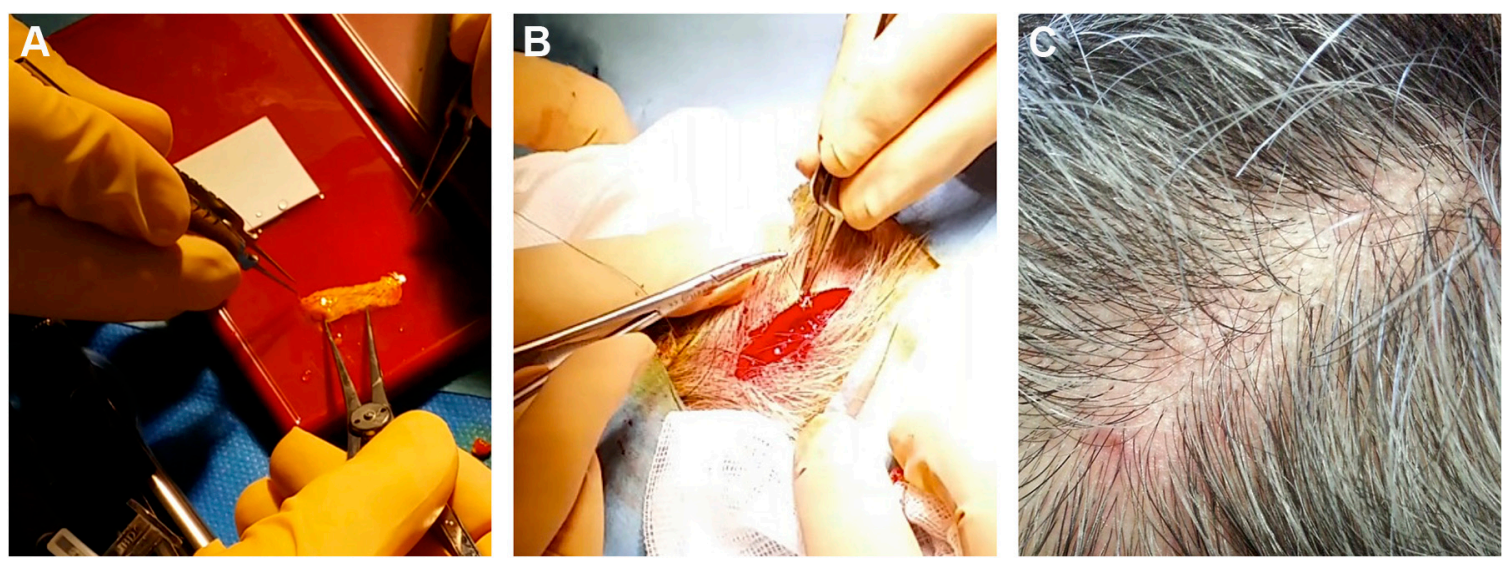

Figure 3 Excision of the temporalis fascia after surgical incision of the temporal scalp.

Notes: (A) Aspect of a $3 \times 1 \mathrm{~cm}$ fragment of superficial temporalis fascia. (B) Wound closure after temporalis fascia excision. (C) Six-month postoperative aspect (patient 3). 


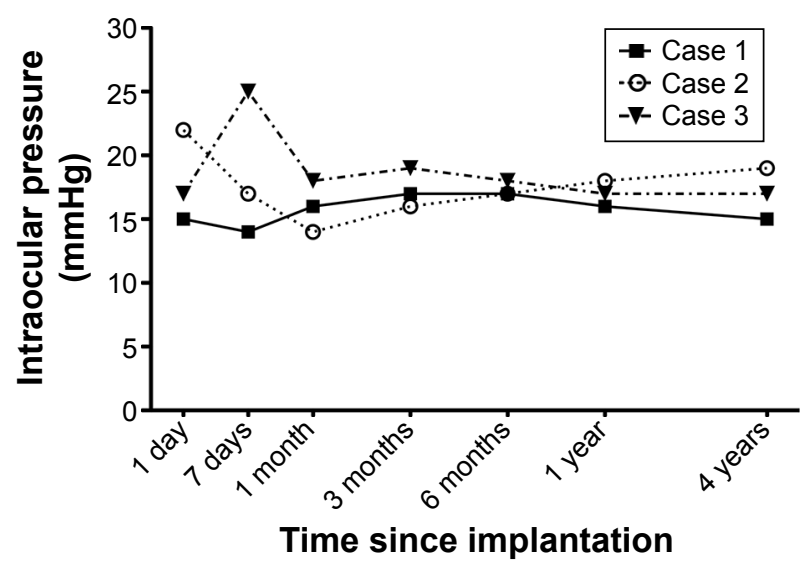

Figure 4 Intraocular pressure trends over the 4-year follow-up in three patients who received the Argus II Retinal Prosthesis System with the adapted technique using a scleral flap and a superficial temporalis fascia autograft.

Note: Argus II Retinal Prosthesis System (Second Sight Medical Products, Inc., Sylmar, CA, USA).

\section{Discussion}

A modified Argus II retinal prosthesis implantation procedure, with a scleral flap and a patch of autogenous temporalis fascia, efficiently prevented ocular hypotony and conjunctival erosion in three subjects. Moreover, these favorable outcomes were prolonged over a 4-year follow-up period, and the graft had a favorable tolerance profile, as expected from an autogenous tissue.

Autogenous grafts of temporalis fascia are frequently used for ophthalmological, maxillofacial, or otorhinolaryngological procedures, such as orbit and eyelid reconstructions following complex traumas or malignancy, ${ }^{10,11}$ tympanoplasty, ${ }^{12}$ nasal septal perforation, ${ }^{13,14}$ or cerebrospinal fluid leak repair. ${ }^{15}$ Fascia sampled from other sites, such as fascia lata, are also often employed for eyelid surgery. ${ }^{16-18}$ Temporalis fascia is a double layer of loose connective tissue. The superficial fascia lies directly below the fatty layer and hair follicles of the scalp; removal of a fragment of superficial fascia is not reversible but is devoid of any functional consequences. ${ }^{19}$ It overlies the deep fascia that covers the temporalis muscle and its aponeurosis (Figure 2). Both lamina are supplied by the middle temporal artery, a branch of the superficial temporal artery that arises below the zygomatic arch. ${ }^{19,20}$ The two layers are similar in terms of collagen content and elasticity, and tend to lose their elasticity upon dehydration. ${ }^{21}$ Thus, keeping the autogenous graft hydrated in an antibiotics solution before reimplantation, as performed in our protocol, helped preserve its mechanical properties.

Since the retinal prosthesis implantation procedure is systematically performed under general anesthesia, the two additional steps had limited consequences in terms of discomfort or additional risk for the patient. The extra time required was $\sim 30$ minutes (25 minutes for the temporalis fascia sampling and 5 minutes for the scleral flap), for a total duration of $\sim 3-5$ hours. At the excision site on the temporal scalp, esthetical consequences were limited since hair growth dissimulated the scar (Figure 3C).

Current and future retinal prosthesis devices are intended to remain implanted for decades. Therefore, a robust wound seal as well as an efficient coverage of the extraocular part of the device, preventing conjunctival erosion, are critical steps. Early and delayed conjunctival erosions may occur after Argus II system implantation. Among possible mechanisms, implantation of subconjunctival material and conjunctival surgery may lead to tear film instability, reduced corneal adhesiveness and delayed tear turnover. ${ }^{22}$ The longterm safety analysis of the 30-patient international study reported a rate of conjunctival erosions of $10 \%$ after 1 year (three patients) and $13 \%$ after 3 years (four patients). ${ }^{3}$ Among reported complications, ocular hypotony was $6.7 \%$ (two patients) through the first year and $13.3 \%$ (four patients) through the 3-year study period. ${ }^{3}$

Processed human or bovine cadaveric pericardium is employed in ocular surgery for scleral wound repair after ocular perforations ${ }^{23}$ or glaucoma surgery with bleb-related
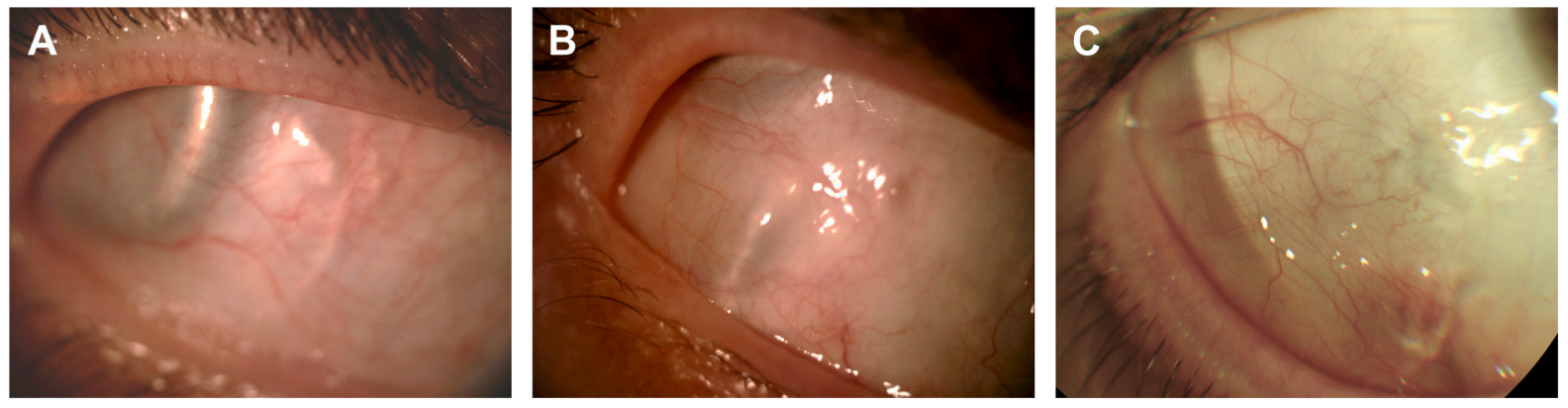

Figure $\mathbf{5}$ Color photographs of the temporal conjunctiva overlying the electronics case 4 years after Argus II retinal prosthesis implantation. Note: No conjunctival erosion or inflammation had been observed over the follow-up period in patient I (A), patient 2 (B), and patient 3 (C). 
complications and excessive filtration. ${ }^{24,25}$ It serves as tectonic support, epithelialization substrate or superficial patch graft and presents a favorable safety profile. Yet, the advantages of autograft over allogenous biological material are multiple. It eliminates the risks of histocompatibility mismatch, of infectious pathogen transmission, either known (human immunodeficiency virus, viral hepatitis, etc) or unknown (prions, etc), and of allergic reaction to products employed for the processing of cadaveric material. Moreover, it is independent from local legislation on human tissue and is cost-effective, since it can be performed with basic surgical instruments and sutures.

In the 30-patient international prospective study evaluating the Argus II retinal prosthesis, the experience from the first 15 implanted subjects proved beneficial, since fewer adverse events were observed with the 15 later enrollees. ${ }^{2}$ Therefore, reports of early surgical and clinical experience, including adapted surgical techniques with this pioneering strategy, ${ }^{26-29}$ should contribute to optimize implantation procedures for Argus II and other forthcoming retinal prosthetic devices. We believe that sharing the lessons learned from initial cases with the growing number of vitreoretinal surgeons who will be implanting these devices, may improve patient safety.

This study has several limitations, including the low number of patients related to the rarity of the procedure, the lack of a control group due to the unavailability of processed pericardium, and the lack of advanced anterior segment imaging to follow scleral and conjunctival changes after temporalis fascia autograft.

Assuming that ocular hypotony and conjunctival erosion would occur at the frequency reported during the international clinical trial, ${ }^{3}$ the study population would need at least 44 patients (based on the lowest frequency, 6.7\%) to detect adverse events with a $95 \%$ confidence interval. Moreover, observing zero adverse events in a study population of three indicates that the $95 \%$ confidence interval for this specific event frequency is $0 \%-63 \% .^{30}$ Therefore, these results should be confirmed on an extended study cohort. As part of a temporary reimbursement authorization for the Argus retinal prosthesis by the French public health authority, the modified implantation technique is currently employed on a larger scale, which will allow this issue to be addressed.

Conjunctival modifications after retinal prosthesis implantation were evaluated clinically, but future studies may also include conjunctival monitoring by anterior segment optical coherence tomography. This noninvasive, high resolution imaging modality allows the exploration of subsurface areas of conjunctival tissue. It enables the postsurgical evaluation of anterior segment features, such as filtering blebs, ${ }^{31}$ and may provide useful knowledge about the adhesive scarring process following implantation of subconjunctival material.

Future developments of retinal prosthesis systems should attempt to reduce the silicone cable caliber to reduce the risk of leak, minimize the size of the extrascleral electronics case to reduce the risk of conjunctival erosion, and develop wireless transmission systems between the intra- and extraocular parts of the devices.

To summarize, superficial temporalis fascia autograft has been employed safely for retinal prosthesis implantation. It may also serve for scleral repair procedures as a substitute to processed cadaveric tectonic tissues, in clinical settings where they are unavailable or not allowed by local regulations. This technique is applicable to all retinal prosthesis devices, and should contribute in minimizing the use of exogenous material for these complex procedures.

\section{Acknowledgments}

The authors thank Michel Tazartes (Quinze-Vingts Hospital, Paris, France) for surgical counseling, Jessy Dorn and Grégoire Cosendai (Second Sight Medical Products, Sylmar, CA, USA) for technical assistance in reviewing the manuscript.

\section{Author contributions}

AM: acquisition, analysis, and interpretation of data; drafting the manuscript. NA: conception and design of the study; took part in revising the manuscript. SM-S: conception and design of the study, acquisition of data; took part in revising the manuscript. J-AS: conception and design of the study, analysis and interpretation of data; took part in revising the manuscript. P-OB: conception and design of the study, acquisition, analysis and interpretation of data; took part in revising the manuscript. All authors have agreed to be accountable for all aspects of the work in ensuring that questions related to the accuracy or integrity of any part of the work are appropriately investigated and resolved, and have given final approval of the version to be published and take public responsibility for appropriate portions of the content.

\section{Disclosure}

AM, NA, and SM-S declare that they have no conflicts of interests in this work. J-AS: stock ownership, consultancies (Pixium Vision). P-OB: reimbursements (Second Sight Medical Products, Inc.). 


\section{References}

1. Ahuja AK, Behrend MR. The Argus ${ }^{\mathrm{TM}}$ II retinal prosthesis: factors affecting patient selection for implantation. Prog Retin Eye Res. 2013; 36:1-23.

2. Humayun MS, Dorn JD, da Cruz L, et al. Interim results from the international trial of Second Sight's visual prosthesis. Ophthalmology. 2012;119(4):779-788.

3. Ho AC, Humayun MS, Dorn JD, et al. Long-term results from an epiretinal prosthesis to restore sight to the blind. Ophthalmology. 2015; 122(8):1547-1554.

4. Dorn JD, Ahuja AK, Caspi A, et al. The detection of motion by blind subjects with the epiretinal 60-electrode (Argus II) retinal prosthesis. JAMA Ophthalmol. 2013;131(2):183-189.

5. Lauritzen TZ, Harris J, Mohand-Said S, et al. Reading visual braille with a retinal prosthesis. Front Neurosci. 2012;6:168.

6. Luo YH-L, Zhong JJ, da Cruz L. The use of Argus ${ }^{\circledR}$ II retinal prosthesis by blind subjects to achieve localisation and prehension of objects in 3-dimensional space. Graefes Arch Clin Exp Ophthalmol. 2015; 253(11):1907-1914.

7. Kotecha A, Zhong J, Stewart D, da Cruz L. The Argus II prosthesis facilitates reaching and grasping tasks: a case series. BMCOphthalmol. 2014;14:71.

8. Sabbah N, Authié CN, Sanda N, Mohand-Said S, Sahel J-A, Safran AB. Importance of eye position on spatial localization in blind subjects wearing an Argus II retinal prosthesis. Invest Ophthalmol Vis Sci. 2014;55(12):8259-8266.

9. Second Sight Medical Products, Inc. Argus ${ }^{\circledR}$ II Retinal Prosthesis System - Surgeon Manual. Sylmar: CA: Second Sight Medical Products, Inc; 2013.

10. Bladen JC, Moosajee M, Tumuluri K, Olver JM. The use of a pleated strip of autogenous temporalis fascia graft for frontalis suspension in recurrent poor levator function ptosis in adult patients. Orbit. 2012;31(2):114-118.

11. Copcu E, Sivrioglu N. The new reconstruction technique in the treatment of the skin cancers located on the eyelid: Posterior temporalis fascia composite graft. Int Semin Surg Oncol. 2004;1(1):5.

12. Khan MM, Parab SR. Comparative study of sliced tragal cartilage and temporalis fascia in type I tympanoplasty. J Laryngol Otol. 2015; 129(1):16-22.

13. Jeon E-J, Choi J, Lee J-H, et al. The role of temporalis fascia for free mucosal graft survival in small nasal septal perforation repair. J Craniofac Surg. 2014;25(2):e164-e166.

14. Kaya E, Cingi C, Olgun Y, Soken H, Pinarbasli Ö. Three layer interlocking: a novel technique for repairing a nasal septum perforation. Ann Otol Rhinol Laryngol. 2015;124(3):212-215.

15. Martín-Martín C, Martínez-Capoccioni G, Serramito-García R, Espinosa-Restrepo F. Surgical challenge: endoscopic repair of cerebrospinal fluid leak. BMC Res Notes. 2012;5:459.

16. Sebastiá R, Fallico E, Fallico M, Fortuna E, Herzog Neto G, Lessa S. Bilateral lid/brow elevation procedure for severe ptosis in KearnsSayre syndrome, a mitochondrial cytopathy. Clin Ophthalmol. 2014:9: $25-31$.

Clinical Ophthalmology

\section{Publish your work in this journal}

Clinical Ophthalmology is an international, peer-reviewed journal covering all subspecialties within ophthalmology. Key topics include: Optometry; Visual science; Pharmacology and drug therapy in eye diseases; Basic Sciences; Primary and Secondary eye care; Patient Safety and Quality of Care Improvements. This journal is indexed on Submit your manuscript here: http://www.dovepress.com/clinical-ophthalmology-journal
17. Roshdy M, Elsamkary M. Clinical trial comparing autogenous fascia lata sling and Gore-Tex suspension in bilateral congenital ptosis. Clin Ophthalmol. 2016;10:405-409.

18. Asamura S, Kakizaki H, Enjyo M, Hashimoto T, Isogai N. Frontalis sling procedure for ocular myasthenia gravis. Clin Ophthalmol. 2012;6: $575-577$.

19. Abul-Hassan HS, von Drasek Ascher G, Acland RD. Surgical anatomy and blood supply of the fascial layers of the temporal region. Plast Reconstr Surg. 1986;77(1):17-28.

20. Davidge KM, van Furth WR, Agur A, Cusimano M. Naming the soft tissue layers of the temporoparietal region: unifying anatomic terminology across surgical disciplines. Neurosurgery. 2010;67(3 Suppl Operative):ons120-129; discussion ons129-130.

21. Wormald PJ, Alun-Jones T. Anatomy of the temporalis fascia. J Laryngol Otol. 1991;105(7):522-524.

22. Napoli PE, Coronella F, Satta GM, Fossarello M. A novel technique of contrast-enhanced optical coherence tomography imaging in evaluation of clearance of lipids in human tears. PLoS One. 2014;9(11): e109843.

23. Alio JL, Rodriguez AE, Martinez LM. Bovine pericardium membrane (tutopatch) combined with solid platelet-rich plasma for the management of perforated corneal ulcers. Cornea. 2013;32(5):619-624.

24. Papaconstantinou D, Georgalas I, Taliantzis S, Koutsandrea C, Ladas I, Georgopoulos G. Human pericardium graft in the management of bleb's complication performed in childhood: a case report. BMC Ophthalmol. 2011;11:27.

25. Raviv T, Greenfield DS, Liebmann JM, Sidoti PA, Ishikawa H, Ritch R Pericardial patch grafts in glaucoma implant surgery. J Glaucoma. 1998; 7(1):27-32.

26. Seider MI, Hahn P. Argus II retinal prosthesis malrotation and repositioning with intraoperative optical coherence tomography in a posterior staphyloma. Clin Ophthalmol. 2015;9:2213-2216.

27. Gregori NZ, Davis JL, Rizzo S. Bimanual technique for retinal tacking of epiretinal prosthesis. Retina. 2016;36(1):199-202.

28. Montezuma SR, Tang PH, van Kuijk FJGM, Drayna P, Koozekanani DD Implantation of the Argus II retinal prosthesis in an eye with short axial length. Ophthalmic Surg Lasers Imaging Retina. 2016;47(4): 369-371.

29. Tran B-K, Wolfensberger TJ. Relation between implant position and perceptual threshold in a patient with epiretinal prosthesis system. Klin Monbl Augenheilkd. 2016;233(4):493-495.

30. Carter RE, Woolson RF. Statistical design considerations for pilot studies transitioning therapies from the bench to the bedside. $J$ Transl Med. 2004;2(1):37.

31. Napoli PE, Zucca I, Fossarello M. Qualitative and quantitative analysis of filtering blebs with optical coherence tomography. Can JOphthalmol. 2014;49(2):210-216.

32. System Overview [webpage on the Internet]. Sylmar, CA: Second Sight Medical Products, Inc.; 2016. Available from: http://www.secondsight. com/system-overview-en.html. Accessed August 2, 2016.

PubMed Central and CAS, and is the official journal of The Society of Clinical Ophthalmology (SCO). The manuscript management system is completely online and includes a very quick and fair peer-review system, which is all easy to use. Visit http://www.dovepress.com/ testimonials.php to read real quotes from published authors. 